\title{
REDESIGN DO CURSO “ATENÇÃO INTEGRAL À SAÚDE DA PESSOA IDOSA I" NA UNIVERSIDADE ABERTA DO SUS/FIOCRUZ: DO AUTOINSTRUCIONAL AO AUTOEDUCACIONAL
}

\author{
BRASÍLIA/DF JUNHO/2018

\begin{abstract}
Thomas Louis Yvon Petit - UNA-SUS/Fiocruz - thomaspetit@unasus.gov.br
Laura Gris Mota - UNA-SUS/Fiocruz - lauramota@unasus.gov.br

Luciana Dantas Soares Alves - UNA-SUS/Fiocruz - lucianaalves@unasus.gov.br

Daniela Fontinele Botelho - UNA-SUS/Fiocruz - danielabotelho@unasus.gov.br

Alex Crispim da Cruz - UNA-SUS/Fiocruz - alexcruz@unasus.gov.br

Márcio Batista da Silva - UNA-SUS/Fiocruz - marciosilva@unasus.gov.br

Lino Vaz Moniz - UNA-SUS/Fiocruz - linomoniz@unasus.gov.br
\end{abstract}

Tipo: Relato de Experiência Inovadora (EI)

Categoria: Métodos e Tecnologias

Setor Educacional: EDUCAÇÃO CONTINUADA EM GERAL

\begin{abstract}
RESUMO
Neste relato apresentamos os resultados do processo de redesign de um curso autoinstrucional, Atenção integral à saúde da pessoa idosa l, criado e ofertado pela secretaria executiva da UNASUS/Fiocruz. O objetivo desse redesign foi explorar as possibilidades e os limites da dinâmica "menos instrução, mais educação". Com o trabalho de design educacional realizado, apontamos o "autoeducacional" como nova perspectiva do autoinstrucional, com foco na ação, na interação e na personalização.
\end{abstract}

Palavras-chave: design educacional, curso autoinstrucional, educação permanente em saúde 


\section{Introdução}

No ciberespaço, os cursos autoinstrucionais permitem e promovem um certo acesso, muitas vezes gratuito, à formação continuada, na perspectiva da educação ao longo da vida característica do século XXI. Esse modelo de educação a distância, como indicou João Mattar (2014, p. 105), é predominante no Brasil.

O autor, entretanto, ressaltou a necessidade de revisar o modelo baseado na instrução individual, defendendo a exploração de um modelo mais flexível e aberto (2014). Nesse sentido, adotando o termo oficial da Classificação Brasileira de Ocupações (CBO), Mattar (2014) sugeriu a definição, nas práticas e nas pesquisas, de um design mais educacional do que instrucional.

O design educacional se diferencia do design instrucional da mesma forma que a educação se diferencia da instrução. "A instrução entrega um passo a passo, um manual, orientações detalhadas de como algo deve ser feito; a educação busca a formação integral do ser humano", segundo Mattar (2014, p. 23). A primeira foca no ensino e na transmissão de conteúdo, enquanto a segunda se interessa pela aprendizagem e pela construção de conhecimentos.

Neste relato, compartilhamos uma experiência de redesign do curso "Atenção à saúde integral da pessoa idosa I", ofertado pela Universidade Aberta do Sistema Único de Saúde (UNA-SUS) da Fiocruz-Brasília, e dirigido a profissionais de saúde. Todos os cursos da instituição, autoinstrucionais, estão disponíveis em acesso aberto em períodos de oferta - com certificação - e no Acervo de Recursos Educacionais em Saúde (ARES) - sem certificação.

O curso foi desenvolvido em html5, no Pacote Padrão UNA-SUS (criado pela equipe UNA-SUS para padronizar a produção de recursos educacionais com persistência de dados e possível visualização e reutilização) e ofertado na plataforma Moodle como parte da formação das equipes do SUS em atendimento à população idosa. Observa-se na Figura 1 que seu conteúdo está dividido em unidades de aprendizagem. Além dessas unidades, há um espaço separado para a avaliação, somativa, principalmente baseada em quiz.

Figura 1 - Home do curso 


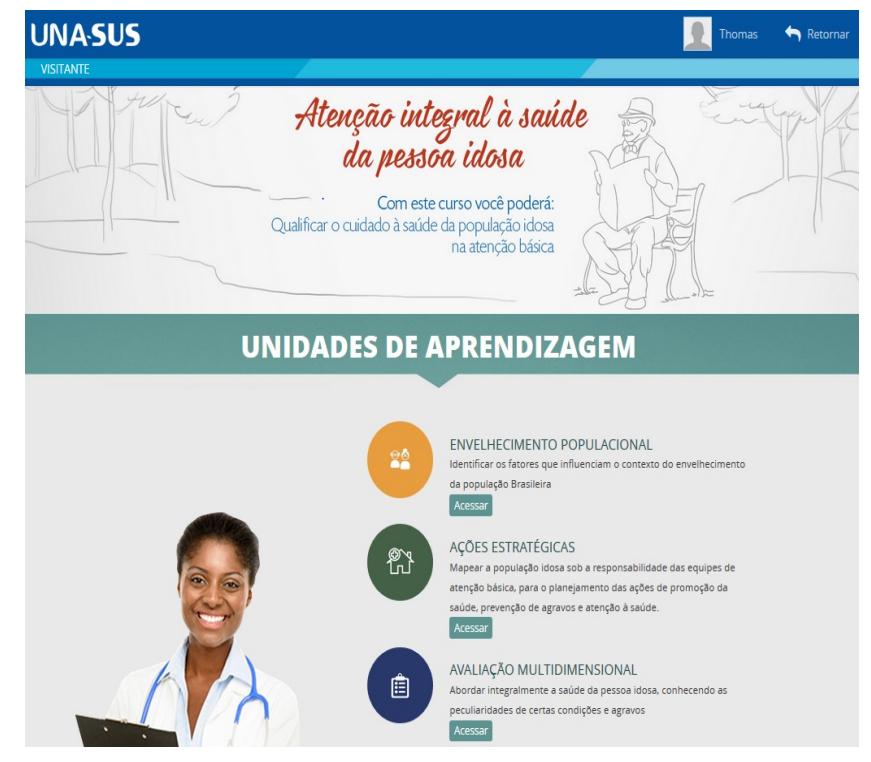

Fonte: elaborada pelos autores

Cada unidade, conforme ilustrado na Figura 2, inclui temas nos quais o conteúdo é apresentado. Esse conteúdo é multimodal, isto é, baseado em texto, imagens e material audiovisual, além de ser completado com material de apoio externo.

\section{Figura 2 - Exemplo de tema na Unidade 1}

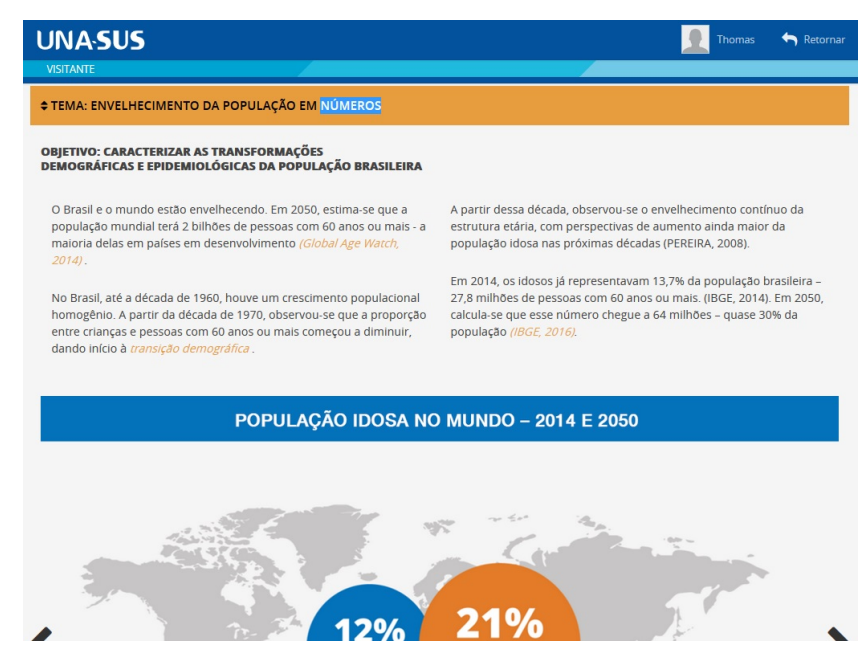

Fonte: elaborada pelos autores

\section{Objetivo}

Considerando o exposto, o objetivo norteador de nosso trabalho foi explorar as possibilidades e os limites da dinâmica "menos instrução, mais educação" no design de um curso autoinstrucional, com a seguinte pergunta em mente: quais as condições, retomando a diferenciação conceitual proposta por Mattar (2014), para passar de 
autoinstrucional a autoeducacional?

\section{Base teórica}

Para o redesign do curso, tomamos como base teórica os trabalhos de João Mattar (2014) sobre o design educacional, bem como as contribuições de David Barton e Carmen Lee (2015) na área da linguagem on-line. Apresentamos a seguir os principais elementos que nos orientaram na experiência relatada.

No design educacional, Mattar (2014) sublinhou a importância de pensar no design de ambiente, de interações e de atividades. O primeiro, o design de ambiente, diz respeito à organização do ambiente de aprendizagem e leva em consideração fatores de natureza humana, didática ou ainda tecnológica.

O uso de aplicativos para smartphone foi evocado pelo autor como uma tendência da educação contemporânea (2014). Os aplicativos, como os websites, representam de fato ambientes de aprendizagem ao alcance da mão dos aprendizes, pois acessíveis com o próprio telefone.

Segundo Barton e Lee, um dos problemas da educação formal é que suas sessões "não condizem com a flexibilidade temporal e espacial das mensagens" criadas pelos aprendentes em usos mais informais das tecnologias digitais (2015, p. 210). Nesse sentido, entendemos que o fator espaço-temporal se torna central no design educacional.

Segundo Mattar (2014), antes de focar no conteúdo em si, o design educacional deve focar na construção de atividades ricas em interações. O design de interações e o de atividades, portanto, acontecem de forma paralela no processo. Nesse sentido, a interatividade promovida pelo ambiente representa um ponto crucial.

Em relação às atividades, o autor sublinhou a relevância de promover, por meio delas, autenticidade (2014). Nas atividades 2.0, segundo Barton e Lee (2015), observa-se uma participação ativa das pessoas, que geram seu próprio conteúdo, bem como um "aprender fazendo" (p. 213). Nessa dinâmica, Mattar (2014) reconsiderou a pertinência da avaliação formal, com prova e notas, no design educacional. O fim da avaliação, segundo o autor, poderia dar um destaque maior ao feedback interativo.

O ciberespaço, que contém textos cada vez mais multimodais e interativos, ainda é mediado, sobretudo, por textos escritos, como ressaltaram Barton e Lee (2015). Isso, 
segundo os referidos autores, envolve novas práticas de letramento; as pessoas estão envolvidas em atividades letradas (2015, p. 27). A consideração dos letramentos digitais mais informais em contextos educacionais on-line é uma questão que não pode ser mais evitada (2015, p. 10).

No ambiente de aprendizagem on-line, as interações podem ser diversas: interação aluno-conteúdo, aluno-aluno, aluno-ambiente, aluno-professor, entre outras ressaltadas por Mattar (2014). Em termos de interação aluno-ambiente, o autor (2014, p. 114) indicou que a adoção de um estilo conversacional permite personalizar o ambiente, gerar um sentimento de presença social e motivar os aprendizes.

\section{Procedimentos metodológicos}

O primeiro passo consistiu em analisar o design inicial (Design 1) do curso "Atenção à saúde integral da pessoa idosa l", segundo três critérios oriundos de nossa base teórica, a saber: a ação, a interação e a personalização.

A análise, com esse filtro, permitiu identificar carências no Design 1, a partir das quais foi feita uma proposta de redesign (Design 2). Um documento de requisitos - funcionais, não funcionais e educacionais - foi elaborado para o Design 2, assim como um mockup, tomado como base ergonômica e visual para o desenvolvimento do curso pela nossa equipe interdisciplinar.

Nas linhas a seguir, apresentamos os principais elementos desse documento e algumas das telas do protótipo realizado a partir do mockup. Propomos uma abordagem comparativa no intuito de mostrar como esses elementos do Design 2 foram pensados para tentar suprir as carências identificadas na análise do Design 1.

\section{Apresentação e discussão dos resultados}

O ponto de partida do redesign foi a dinâmica mobile first, tendo em conta a influência dos aplicativos para smartphone nas práticas on-line cotidianas. Isso significa que, em vez de criar um ambiente desktop responsivo - isto é, automática e ergonomicamente adaptável a telas de celulares e tablets - nossa estratégia de conteúdo foi orientada pelo desejo de aprimorar o diálogo entre a forma e o fundo, numa perspectiva mobile.

Assim sendo, nossa proposta de redesign consistiu em distribuir o conteúdo dos temas do Design $1 \mathrm{em}$ formato de flashcard, conforme ilustrado na Figura 3. Cada tema oferece uma situação de aprendizagem curta e personalizável, com microtextos - 
escritos, imagéticos ou audiovisuais - que possibilitam aos aprendizes terem uma consciência maior - e eventualmente fazerem uma melhor gestão - de seu tempo de interação com o conteúdo do curso.

Figura 3 - Flashcards do Design 2 (versão mobile)
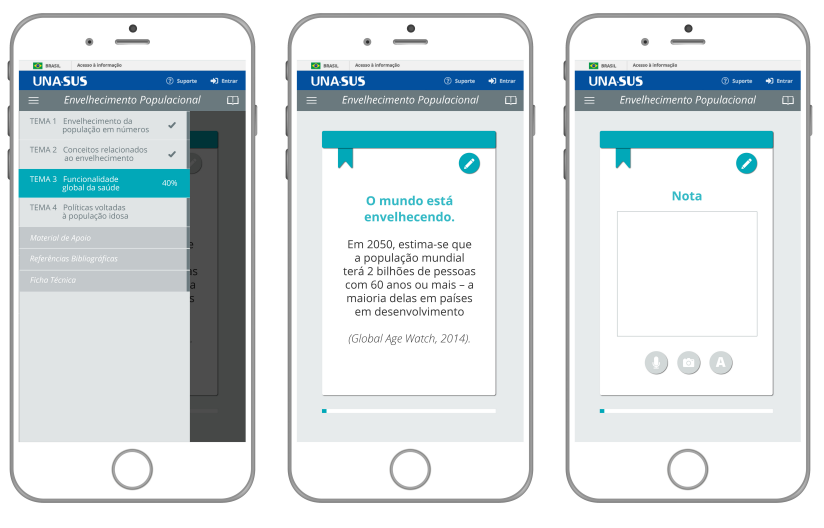

Fonte: elaborada pelos autores

A partir do formato de flashcard, pensamos em ferramentas que pudessem incentivar mais ação dos aprendizes, mais interação com o conteúdo e uma maior personalização do percurso. Na Figura 3, observa-se que no próprio flashcard inserimos duas ferramentas: o bookmark, que permite filtrar o conteúdo, e a anotação, que permite criar um texto multimodal - texto, áudio, imagem - e, assim, interagir com o conteúdo de forma personalizada.

Depois da visualização de todos os flashcards de conteúdo do tema, um resumo final é pedido aos aprendizes. O conteúdo desse flashcard, portanto, é gerado por eles mesmos. Essa atividade de síntese foi integrada para incentivar a reflexão e a autointeração. Esta, segundo Mattar (2014, p. 136), "[e]nfatiza a importância do diálogo interno que os alunos estabelecem consigo mesmos durante o envolvimento com 0 conteúdo da aprendizagem. Inclui, portanto, as reflexões dos alunos sobre o próprio conteúdo".

Barton e Lee, corroborando esse argumento, indicaram que "[a] reflexividade, que é a autorreflexão que leva à ação, é central nas teorias de aprendizagem adulta" (2015, p. 175). Ainda, "[a] ideia é que as pessoas reservam espaço e tempo para refletir sobre suas experiências; e é por meio dessa reflexão que elas transformam suas experiências em aprendizagem" (p. 175).

Todas as novas ferramentas do Design 2 - bookmark, anotação, resumo - estão ligadas 
à e-caderneta. Neste novo espaço personalizado, ilustrado na Figura 4, são registrados os flashcards com bookmarks e anotações, bem como os flashcards-resumos gerados pelos aprendizes.

\section{Figura 4 - e-caderneta como espaço personalizado do Design 2}

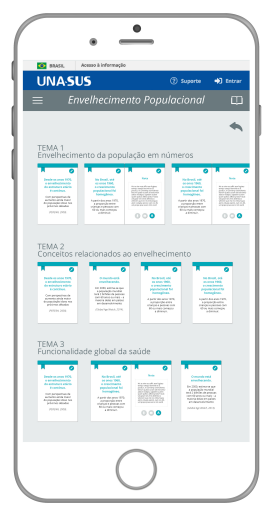

Fonte: elaborada pelos autores

O nome "e-caderneta", abreviada "e-cad", foi escolhido a fim de manter uma consistência com a área do curso - a saúde - e pelo fato de ser, na mesma, um instrumento de referência possibilitando um acompanhamento e um registro personalizado. Cada e-cad, então, será única.

A recepção do conteúdo, tal como era no Design 1, se tornou um processo ativo no Design 2: os aprendizes filtram o conteúdo existente e podem criar o seu. Com o bookmark, a anotação e o resumo final, portanto, a interação com o conteúdo, em cada tema, se tornou em si uma atividade autêntica.

Esta, efetivamente, integra alguns dos princípios de autenticidade propostos por Herrington, Reeves e Oliver (2006), citados por Mattar (2014, p. 132):

- oferece uma oportunidade para a reflexão;

- visa a criação de um produto completo: a e-cad, no final do curso, pode ser exportada e salva. Além disso, ela permite que os aprendizes - profissionais de saúde - possam acessar fácil e rapidamente seu conteúdo, caso precisarem no ambiente de trabalho;

- está naturalmente integrada com a avaliação: a criação da e-cad, em si, simboliza a participação dos aprendizes, novo critério de avalição.

Em relação à avaliação, cabe ressaltar que no Design 1 a consulta do conteúdo das unidades de aprendizagem não era exigida para a certificação. De um ponto de vista 
técnico, efetivamente, os alunos podiam fazer diretamente as atividades de avaliação sem entrar nas unidades. Nesse sentido, a interação com o conteúdo não era valorizada pelo formato.

O Design 2, não apresenta uma avaliação formal somativa. As atividades de avaliação do Design 1 foram transformadas, como sugere a Figura 5, em atividades pedagógicas distribuídas nos diferentes temas/módulos (em azul nos diagramas). A inovação (amarelo nos diagramas), em tal contexto, consiste então na possibilidade de interações aluno-conteúdo e aluno-self (consigo mesmo).

Figura 5 - diagramas de casos de uso do Design 1 e do Design 2

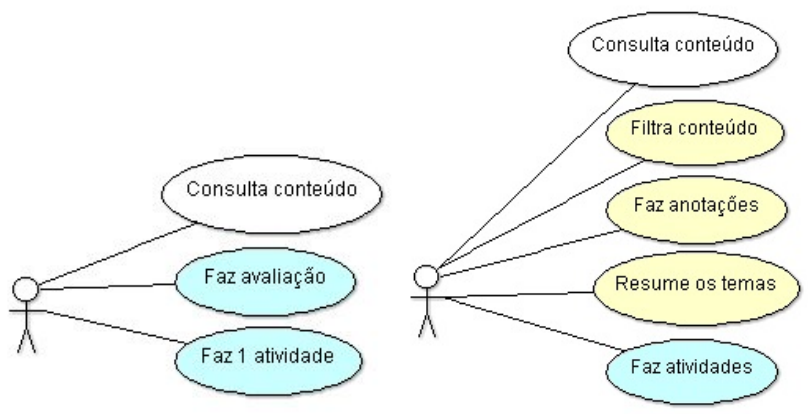

Fonte: elaborada pelos autores

O diagrama de atividades ilustrado na Figura 6 mostra com mais detalhes o ciclo de participação dos aprendizes. O critério de conclusão - e certificação - do curso, em vez de considerar a nota de uma avaliação formal somativa, se baseia na consulta aos flashcards de todos os temas do módulo (que substituiu a unidade) e, nesse sentido, na participação nas atividades propostas no percurso.

\section{Figura 6 - diagrama de atividades do Design 2}

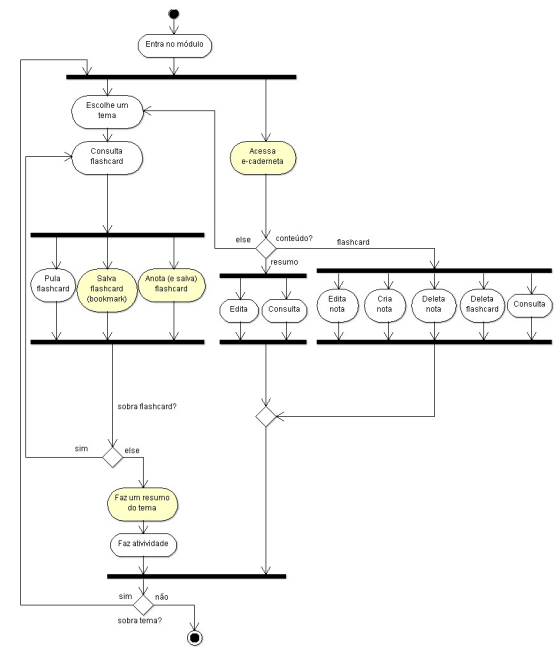


Fonte: elaborada pelos autores

Acreditamos que o fato de assegurar a qualidade do percurso - com critérios de ação, interação e personalização - dispensa um modelo de avaliação formal, que pode soar ultrapassado na perspectiva do design educacional. Pode-se inferir que basear a avaliação na participação, num curso autoinstrucional, desafia os profissionais envolvidos no design educacional a buscar mais qualidade para a experiência de aprendizagem projetada.

Em termos de interações aluno-ambiente, privilegiamos um estilo dialógico, mais interativo e pessoal, de acordo com nossa base teórica. Assim, onde o diálogo era possível, em vez de frases impessoais adotamos a terceira pessoa do singular (você), numa abordagem mais envolvente. Por exemplo, "O profissional de saúde deverá conhecer [...]" se tornou "Como profissional da saúde, você deverá [...]".

Finalmente, é preciso sublinhar que, embora o redesign tenha partido da lógica mobile first, como indicado anteriormente, o design de ambiente da versão desktop considerou as características próprias. Nesse sentido, o formato do flashcard, conforme ilustrado na Figura 7, é apresentado de forma adaptada na tela do computador.

\section{Figura 7 - Flashcards do Design 2 (versão desktop)}

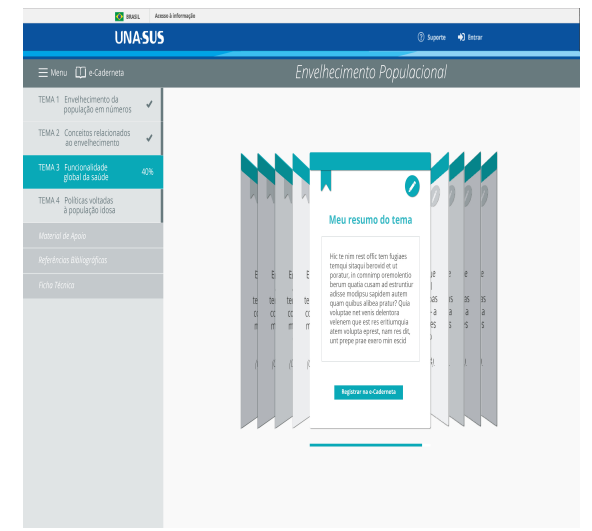

Fonte: elaborada pelos autores

\section{Considerações finais}

A experiência apresentada neste relato nos permitiu explorar as possibilidades e os limites da dinâmica "mais educação menos instrução" no design de um curso autoinstrucional, de acordo com nosso objetivo inicial.

Em termos de possibilidades, mostramos que o formato, as ferramentas e a linguagem adotados no novo design promoveram a ação dos aprendizes, diversos tipos de interação - incluindo a reflexão -, além da personalização do percurso e dos resultados. Essas são condições que, a nosso ver, tornam viável a transição do autoinstrucional ao 
autoeducacional.

Em vez de transmitir conteúdo aos aprendizes e tentar verificar se o assimilaram, apresentamos a informação com atividades interativas e reflexivas que Ihes permitam construir seu próprio conhecimento. Para cursos instrucionais que atendem às vezes a milhares de pessoas espalhadas pelo Brasil, com uma diversidade de perfis, nos parece ser um primeiro passo viável, em termos didáticos e técnicos.

Além disso, as ferramentas escolhidas possibilitam a geração de dados, quantitativos e qualitativos, que nos permitirão avaliar a efetividade do novo design e, inclusive, continuar o redesign, no intuito de aprimorá-lo ao longo das ofertas do curso. Esses dados permitirão traçar perfis mais refinados da comunidade de aprendizes e avaliar a relevância do conteúdo, das atividades e das ferramentas propostos.

No que diz respeito aos limites, o tamanho da comunidade discente, justamente, torna difícil, em termos de mediação técnica e humana, uma interação alunos-alunos, como criação e compartilhamento de conteúdo. Com as contribuições da inteligência artificial, talvez seja mais viável, no futuro, mas em 2018 esse ainda é um dos principais limites do autoeducacional.

Finalmente, a questão da autonomia dos aprendizes, ou ainda das estratégias de aprendizagem, pode ser um objeto de estudo central na área. Trata-se de achar um equilíbrio entre outorgar mais controle e liberdade aos aprendizes de agir sobre e interagir com o conteúdo, e guiá-los para poder aproveitar esse autocontrole e essa liberdade no processo de aprendizagem.

\section{Referências}

BARTON, David; LEE, Carmen. Linguagem online: textos e práticas digitais. São Paulo: Parábola Editorial, 2015.

MATTAR, João. Design educacional: educação a distância na prática. 1. ed. São Paulo: Artesanato Educacional, 2014. 